\title{
Quasi-realism and Relativism
}

\author{
A. W. MOORE \\ St. Hugh's College
}

1. If it is true that 'an ethic is the propositional reflection of the dispositions and attitudes, policies and stances, of people,' as Simon Blackburn says in summary of the quasi-realism that he champions in this excellent and wonderfully provocative book (p. 310), then it seems to follow that different dispositions, attitudes, policies and stances-different conative states, for short-will issue in different ethics, each with an equal claim to truth; and this in turn seems to be one thing that could be reasonably meant by that slippery polyseme 'relativism'. If such relativism does follow, a good deal remains to be said about how much force it has. At the limit it might do no more than signal the abstract possibility of an ethic rivalling that of humans. More potently, it might somehow legitimize the different ethics of different groups of humans in actual conflict with one another. But without the possibility of some such variability of ethic to match a possible variability of conative state, the quasi-realist's claim that an ethic 'reflects' a particular combination of conative states appears hollow.

In the splendid final chapter of his book, and again in the appendix, Blackburn nevertheless tries to keep relativism at bay. Carefully distinguishing some of the many different things that 'relativism' can mean, he argues, with respect to each, either that he is not committed to it or that it does nothing to imply that our own ethic is in any interesting sense 'just' ours. But I want to suggest that Blackburn is committed to a form of relativism whereby our own ethic indeed is in some interesting sense 'just' ours (for some interesting value of 'we').

The relativism in question is not the view that, had our conative states been different, different ethical standards might have applied; Blackburn has persistently and persuasively argued that he is not committed to anything like that. Nor is it the view that, had our conative states been different, we might have applied different ethical standards; that is a platitude (and scarcely merits the label 'relativism'). The view is something lying subtly between these, namely that, had our conative states been different, we might have applied different ethical standards and it might have been right for us to do so; we 
might have had different ethical beliefs and those different ethical beliefs might have been true.

But does this not collapse into the first view? I think not. I think it admits of an 'opaque' reading that keeps it separate from the first view. Here is an analogy. It is now 2 p.m. Had I caught that flight to Australia, it would still now have been 2 p.m. However, I would have thought that it was midnight and it would have been right for me to do so; my belief about what time it is would have been true. Its now being 2 p.m. is 'just' a feature of my current location. ' (Later, I shall suggest a somewhat more refined model for the opacity. For now, I am content merely to identify the kind of relativism that I think quasi-realism yields.)

2. Blackburn is uneasy about the 'just' in the claim that our ethic is 'just' ours. He hears it as an invitation to accept the first of the views mentioned above, the view whereby different ethical standards might have applied (or worse still, that 'over there' different ethical standards do apply). This in turn is because he takes the relativist's even-handedness in pitting our ethic against possible rivals as itself an ethical stance. He hears the relativist as saying that another ethic might have been (or worse still, is) as good ethically as ours; that it might have been ethically right for us to apply different ethical standards (e.g. pp. 305 and 314). But relativism of the sort I am envisaging no more involves adopting a particular ethical stance than relativism about what time of day it is involves adopting a particular location. It is a metaphysical view.

3. Why does Blackburn not acknowledge the possibility of 'metaphysical' even-handedness? Ironically, I think that he himself helps to give an effective diagnosis.

Several times in the book he refers to what he calls 'Ramsey's ladder'. This is a series of propositions each of which, bar the first, looks as if it is on a higher level than its predecessor (in the sense of being substantially about its predecessor) though in fact they all have the same content; as Blackburn puts it, 'Ramsey's ladder is horizontal' (pp. 78-79 and 294-97). Thus if the first proposition in the series is that $p$, then further along are such propositions as that it is true that $p$, that it is a fact that it is true that $p$, and the like.

Purists may prefer to put it this way: had I caught that flight to Australia, I would have been prepared to assert the sentence, 'It is midnight,' and any such assertion would have been true. The worry then is that, while this makes the opacity plainer, it seems also to make the analogy more anodyne. Does it? Not really. It is not as if the meaning of the sentence is irrelevant. There is more transparency than that. The sentence I would have been prepared to assert in Australia is the very sentence $I$ hereby deny in insisting that it is not midnight. (For an excellent exchange relating to some of the issues raised by this analogy, and by what I shall say later, see Perry and Blackburn (1986).) 
Now Blackburn is quite right to say that Ramsey's ladder is horizontal. However, he sometimes makes this sound like an exciting philosophical thesis (e.g. p. 79), whereas it is really just a matter of definition. For obviously it is not impossible to produce a proposition of this general stripe that is on a higher level than the proposition that $p$; it is just that what is produced will not then count as being on Ramsey's ladder. In particular, if the proposition that $p$ is an ethical proposition, then it is not impossible to produce a meta-ethical proposition, off the ladder, about what makes it true that $p$. Blackburn himself insists on this, in opposition to Ronald Dworkin (p. 295) - as of course he must, for quasi-realism itself involves producing just such propositions. (It would be bad news indeed for Blackburn if an opponent of quasi-realism, having first affirmed that $p$, went on to express his opposition to quasi-realism by insisting that it was 'non-quasi-realistically' true that $p$, and was able to justify this on the grounds that he was crawling along Ramsey's ladder!)

Blackburn's chief concern about Ramsey's ladder is the danger of our crawling along it while thinking that we are moving vertically. But there is also the danger of our moving vertically while thinking that we are crawling along the ladder. It seems to me that Blackburn is so keen to avoid the first of these dangers that he succumbs to the second. And this is what prevents him from acknowledging the relativist consequences of his quasi-realism. He cannot hear the relevant debate about relativism as other than a ground-level debate; the relevant endorsements of relativism as other than attempts to deny propositions on Ramsey's ladder (pp. 295-96). ${ }^{2}$

4. Very well, then; could Blackburn distance himself from the relativism that I am trying to pin on him by arguing that ultimately only one combination of conative states is genuinely possible? No. If such a thing could be argued at all, then either 'genuinely possible' would be doing ethical work, in which case this would be another ground-level failure to engage properly in the

2 There is a graphic illustration of this in Blackburn (1999), p. 217, where, having once again shown how quasi-realism enables us to crawl along Ramsey's ladder, he continues, 'And why does that not imply that divergent moral opinions are on all fours? Well, all I can hear that as meaning is that they are all equally good,' (his emphasis). There is also an interesting echo of it elsewhere in the book, namely in his remarks on Bernard Williams' well known rejection of the possibility of external reasons (pp. 264-66). While substantially agreeing with Williams, Blackburn nevertheless urges that there is a "use of "external reasons" in which there are such things' (p. 266), the use in question being a ground-level use, in contrast with the higher-level use that is needed to state Williams' view.-I am far from denying, incidentally, that there are some debates in philosophy which are spurious because they purport to involve a higher-level use of certain expressions which is simply not available: the expressions are to be understood in groundlevel terms if at all. (See further my (1997), esp. Ch. 6, §1; and cf. Wittgenstein (1961), 5.64.) But as I have already intimated, Blackburn cannot dismiss the relevant debate about relativism as a case in point without endangering his own quasi-realism. 
debate, or it would be doing meta-ethical work, in which case this would be an implicit rejection of quasi-realism, in favour of some much more robust kind of realism. (Not that I am making any points here that Blackburn himself does not in effect make-and with effect too (see e.g. pp. 302-03 and 308-10).)

5. But surely, someone might say, there is something untoward in my claim that Blackburn's quasi-realism entails relativism, as we can see if we look at the analogue of Blackburn's view for modality. (Let us call this analogue 'modal quasi-realism', as distinct from the 'ethical quasi-realism' that has been our concern up to now.) There are many forms that modal quasi-realism can take, but they all involve a core thesis to the effect that propositions about what is or is not possible reflect certain commitments that people have made-whether these be decisions to adopt certain linguistic conventions (a form I myself favour) or archived failures to make anything of certain ways of thinking (a form Blackburn favours) or something else besides. ${ }^{3}$ Now if my claim about ethical quasi-realism is correct, then a parallel claim about modal quasi-realism must be correct too; that is to say, modal quasi-realism must also entail relativism, in the form, roughly, that we might have acknowledged different possibilities and it might have been right for us to do so. However, while there may be room to deny that the relativism about ethics is itself an ethical view, there is no denying that this is a modal view, a view about what is possible. As such, it cannot help but compromise our modal commitments. Since modal quasi-realism is meant precisely to respect our modal commitments, the claim that it entails such relativism thus becomes the basis of a quick reductio ad absurdum of it. But this in turn casts doubt on the claim, because, whatever problems modal quasi-realism faces, it is too robust a doctrine to be dismissed as quickly as that. ${ }^{4}$

There is much that could be said in response to this worry. (Some would respond to it by saying that modal quasi-realism can indeed be dismissed as quickly as that; but not I, for, as I have already indicated, I favour a form of modal quasi-realism.) It is certainly not obvious that the relativism about modality compromises our modal commitments. At any rate we must beware of thinking that it does so for purely structural reasons. The mere fact that it is (in this context) a ground-level view does not mean that it automatically poses a threat to whatever other ground-level views we have. The corresponding ground-level ethical relativism would have compromised our conative

3 For Blackburn's views, see esp. his (1993); see also his (1984), pp. 216-17. It is interesting to compare Blackburn's views with those of Descartes, as superbly expounded by Jonathan Bennett in his (1994).

4 The worry expressed in this paragraph is related to the problems that Blackburn himself discusses concerning the enterprise of giving a naturalistic explanation of our modal commitments: see $\S \mathrm{VI}$ of his (1993). 
states not just because it was (in that context) a ground-level view, but because it was the particular ground-level view it was: namely, that rival ethics are as worthy of our approval as our own, something we cannot concede without losing our grip on our own.

But still, the worry persists. For just as we cannot concede the worthiness of rival ethics without losing our grip on our own, so too, surely, we cannot concede the possibility of rival arithmetics (say) without losing our grip on our own, or, more to the point, without losing our grip on its necessity. To be sure, we must not forget the opacity in the claim that rival arithmetics are possible. To say that they are-to say that we might have acknowledged different arithmetical possibilities and that it might have been right for us to do so-is not yet to say that any arithmetical falsehoods might have been true. Even so, it looks as if we cannot dissociate saying the first of these from saying the second unless we adopt a very weak modal logic, denying, for instance, that what is possibly possible is eo ipso possible; and it is doubtful that modal quasi-realism on its own can force us to do that. (After all, could not our modal commitments include a commitment to S5?)

In reply: this still betrays an insufficient grasp of the opacity. The opacity is not just a matter of iterated modalities resisting reduction. (If it were, then conceding the possibility of rival arithmetics would force us to adopt a modal logic that was even weaker than suggested; so weak, in fact, as to call into question our title to the claim to be talking about modality at all. For it would force us to deny that what is possibly necessary is eo ipso possible.) The point is this. Had we acknowledged different arithmetical possibilities, and had it been right for us to do so, this would have shown that we were using different concepts. For to say that we might have acknowledged different arithmetical possibilities is not, at least in this context, to say that we might have acknowledged the arithmetical possibility of propositions that we currently take to be arithmetically impossible. It is to say rather that we might have acknowledged the arithmetical possibility of propositions that we currently lack the concepts even to express. ${ }^{5}$ We can concede that rival arith-

5 Why in that case would our rival arithmetic have counted as an arithmetic? Because of a family resemblance. This shows up in the fact that if, starting from here, we were to come to adopt such an arithmetic, then we might well find it natural to use standard arithmetical vocabulary to couch it. For instance, we might find it natural to assert the sentence, ' $7+5>5+7$, - although we would not then be using the terminology in what we currently recognize as a standard way.-And how does this square with what I said above in note 1 about the relevance of the meaning of the sentence 'It is midnight' to what time I would have thought it was if I had been in Australia? Well, there certainly seems to be even greater opacity in this case. But the family resemblance ensures that there is still not total opacity. Suppose we did come to use ' + ' to stand for a noncommutative function, in such a way that we were entitled to assert, ' $7+5>5+7$.' Our use of the symbol might nevertheless be sufficiently like our current standard use of it to warrant our saying that it still stood for an addition function. (We do after all talk naturally about the non-commutative 'addition' of transfinite ordinals-and we do find it 
metics are possible, then, without losing our grip on the necessity of our own, just as we can concede that non-Euclidean geometries are possible without losing our grip on the necessity of the proposition that between any two Euclidean points there is at most one Euclidean straight line.

But in saying this, have I not deprived the relativism of any sting? of course we might have had different concepts. If the ethical relativism that I am trying to pin on Blackburn amounts to no more than that-if it amounts to the claim that, had our conative states been different, we might have had different ethical concepts - then is it not after all a platitude that he can accept with equanimity?

I am certainly happy to admit that this is, in part, what the ethical relativism I am trying to pin on Blackburn amounts to. (That was what I had in mind when I referred earlier to the 'somewhat more refined model for the opacity'. We might have had different ethical beliefs, not just in the sense that we might have had ethical beliefs whose negations were of the same type as those we currently have, but also in the sense that we might have had ethical beliefs that we currently lack the concepts even to formulate.) But I deny that this is a platitude. The different ethical concepts that we might have had would have been the sort of thing that Bernard Williams has famously christened 'thick' ethical concepts. That is to say, they would have been concepts whose applicability was both 'action-guiding' and 'world-guided', of such a kind that even to think in those terms required having certain conative states. $^{6}$ (Blackburn himself more than once refers to concepts of this kind (see p. 303 and the last sentence of his answer to Q.9 on p. 314).) It is no platitude to say that we might have had different concepts of such a kind, corresponding to our different conative states, and that it might have been right (in some non-ethical sense) for us to do so. On the contrary: it is a way of acknowledging that our own thick ethical concepts, and therewith the ethic that we use them to express, are in some interesting sense 'just' ours.

\section{References}

Bennett, Jonathan (1994), 'Descartes' Theory of Modality', in Philosophical Review 103

Blackburn, Simon (1984), Spreading the Word: Groundings in the Philosophy of Language (Oxford: Oxford University Press)

Blackburn, Simon (1993), 'Morals and Modals', reprinted in his Essays in Quasi-Realism (Oxford: Oxford University Press)

Blackburn, Simon (1999), 'Is Objective Moral Justification Possible on a Quasi-Realist Foundation?', in Inquiry 42

natural to use the symbol ' + ' to stand for this function. Think also of the way in which both Euclidean and non-Euclidean geometries are said to treat of points and lines.)

6 See Williams (1985), pp. 140-48. 
Moore, A. W. (1997), Points of View (Oxford: Oxford University Press)

Perry, John and Blackburn, Simon (1986), 'Thought Without Representation', in Proceedings of the Aristotelian Society Supp. Vol. 60

Williams, Bernard (1985), Ethics and the Limits of Philosophy (London: Fontana)

Wittgenstein, Ludwig (1961), Tractatus Logico-Philosophicus, trans. D. F. Pears and B. F. McGuiness (Routledge \& Kegan Paul) 